

\section{REVISTA \\ TEORÍA Y PRÁCTICA \\ DE LA \\ ARQUEOLOGÍA HISTÓRICA LATINOAMERICANA}

ISSN: 2250-866X (impreso) | ISSN: 2591-2801 (en línea)

AÑo VIII, VOLUMEN 8, PRIMAVERA DE 2019

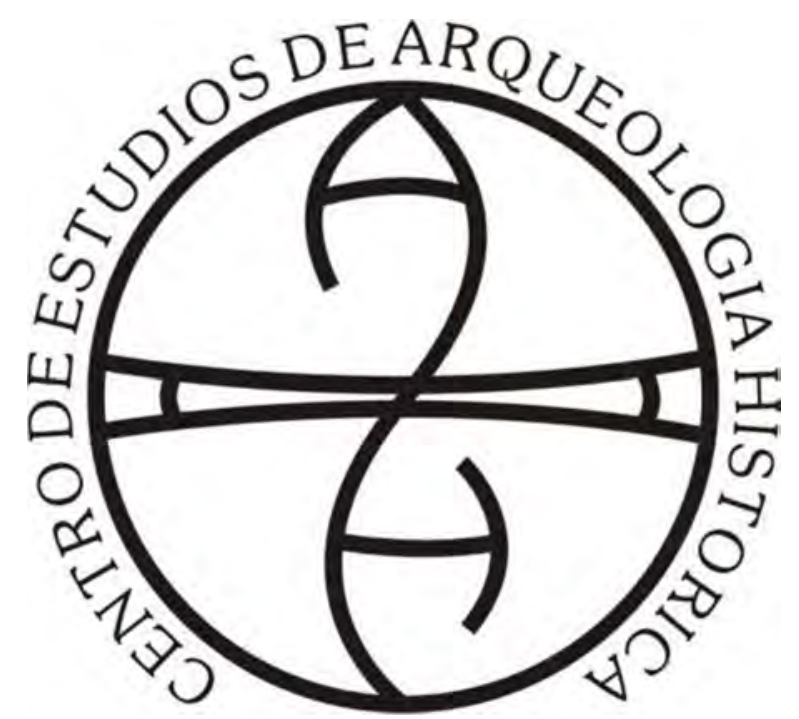

Centro de Estudios de Arqueología Histórica

FACULTAD DE HUMANIDADES Y ARTES | UNIVERSIDAD NACIONAL DE ROSARIO 
(Universidad Nacional de Rosario, Universidad Nacional de Río Cuarto,

Universidad Nacional de San Juan, Universidad de la República, Universidad Nacional de Trujillo)

\author{
AUTORIDADES DE LA UNIVERSIDAD NACIONAL DE ROSARIO \\ RECTOR: Lic. Franco Bartolacci \\ VICE-RECTOR: Od. Darío Macía \\ SECRETARIO GENERAL: Prof. José Goity \\ SECRETARIA ACADÉMICO Y DE APRENDIZAJE: Dr. Marcelo Vedrovnik \\ SECRETARÍA DE CIENCIA TECNOLOGÍA E INNOVACIÓN \\ PARA EL DESARROLLO: Ing. Guillermo Montero.
}

\author{
AUTORIDADES DE LA FACULTAD DE HUMANIDADES Y ARTES \\ DECANO: Prof. Alejandro Vila \\ VICEDECANA: Prof. Marta Varela \\ SECRETARIA ACADÉMICA: Dra. Marcela Coria
}

\author{
AUTORIDADES DEL CENTRO DE ARQUEOLOGÍA HISTÓRICA \\ DIRECTORA: Dra. Ana Rocchietti \\ SECRETARIA: Prof. Nélida de Grandis \\ PROSECRETARIA: Lic. Marianela Bizcaldi
}

DIRECTORAS - EDITORAS:

Dra. Ana Rocchietti y Prof. Nélida De Grandis

SECRETARIA DE EDICIÓN: Dra. Irene Dosztal

Este número es co-edición de las ponencias

del VIII Congreso Nacional de Arqueología Histórica (2018) entre:

Centro de Estudios en Arqueología Histórica: Directora Ana Rocchietti

Centro de Estudios en Arqueología Regional: Director Fernando Oliva

Centro de Estudios en Arqueología Subacuática: Directora Mónica Valentini

Departamento de Arqueología, Escuela de Antropología: Director Fernando Oliva
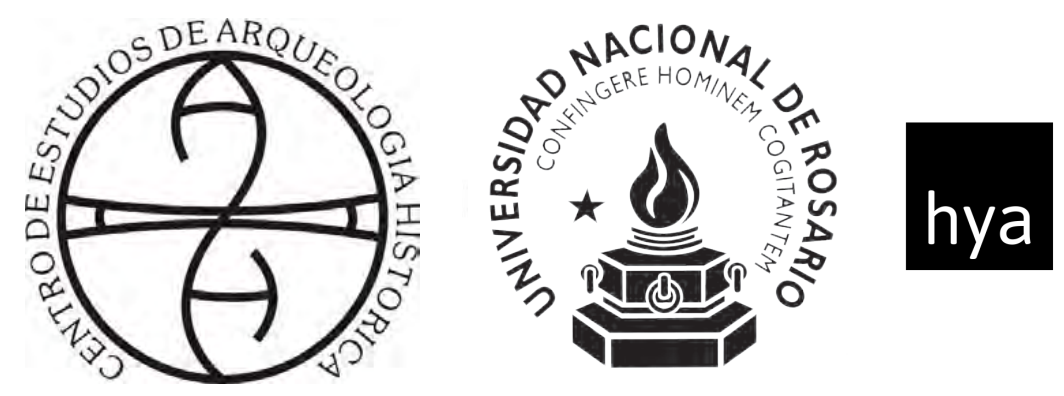

Facultad de Humanidades

y Artes_UNR
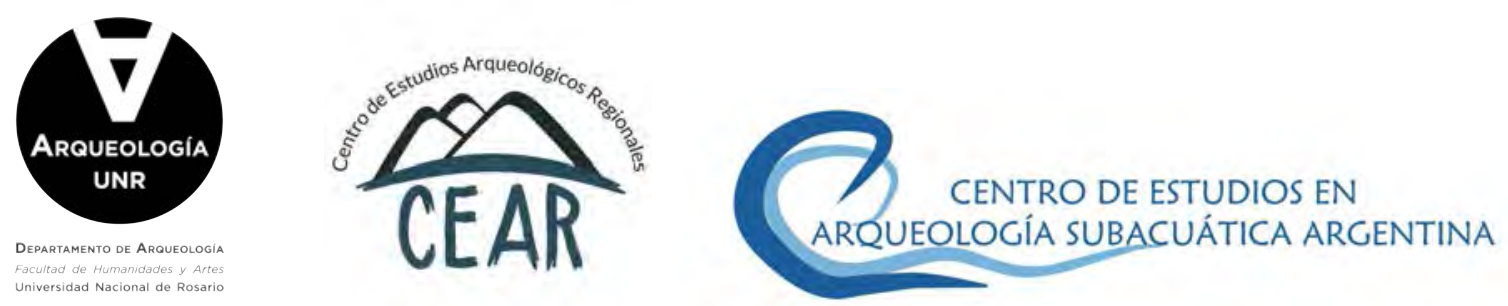
Comité Permanente de los Congresos Nacionales de Arqueología Histórica

Dr. Daniel Schávelzon (Universidad Nacional de

Buenos Aires)

Prof. María Teresa Carrara (Universidad Nacional de Rosario)

Prof. Carlos Baldassarre (Museo Municipal de Río

Grande, Tierra del Fuego) in memoriam

Dr. Mariano Ramos (Universidad Nacional de Luján, CONICET)

Dr. Horacio Chiavazza (Universidad Nacional de Cuyo)

Dra. Ana María Rocchietti (Universidad Nacional de

Rosario, Universidad Nacional de Río Cuarto)

Lic. Facundo Gómez Romero (Universidad Autónoma

de Barcelona)

\section{Comité Científico}

Dra. Tânia Andrade Lima (Universidade Federal do Rio de Janeiro)

Prof. Réginald Auger (CELAT/Département des

Sciences Historiques, Université Laval, Canadá)

Dr. Roberto Bárcena (Universidad Nacional de Cuyo, CONICET)

Dra. Marta Bonaudo (Universidad Nacional de Rosario, CONICET)

Dr. Leonel Cabrera (Universidad de la República, Uruguay)

Dr. Luis María Calvo (Universidad Católica de Santa

$\mathrm{Fe})$

Prof. Juan Castañeda Murga (Universidad Nacional de

Trujillo, Perú)

Dr. Carlos Ceruti (Museo de Ciencias Naturales y

Antropología "Prof. Antonio Serrano". Paraná)

Dr. Horacio Chiavazza (Universidad Nacional de Cuyo)

Dra. Silvia Cornero (Universidad Nacional de Rosario)

Prof. Pedro Paulo Funari (Universidade Estadual de

Campinas, Brasil)

Lic. Jorge A. Gamboa Velásquez (Universidad Nacional

Santiago Antuñez de Mayolo, Perú)

Dr. Eduardo Alejandro García (Universidad Nacional de

San Juan, CONICET)

Prof. Nélida De Grandis (Universidad Nacional de

Rosario)

Dr. Juan Bautista Leoni (Universidad Nacional de

Rosario, CONICET)

Dra. Amancay Martínez (Universidad Nacional de San

Luis)

Dra. Catalina Teresa Michieli (Universidad Nacional de

San Juan, CONICET)

Lic. Fernando Oliva (Universidad Nacional de Rosario)

Ing. Adrián Pifferetti (Universidad Tecnológica
Nacional Regional Rosario)

Dr. Mariano Ramos (Universidad Nacional de Luján, CONICET)

Dra. Ana María Rocchietti (Universidad Nacional de Rosario)

Dr. Daniel Schávelzon, (Universidad Nacional de Buenos

Aires, CONICET)

Dra. Carlota Sempé (Universidad Nacional de La Plata)

Dr. Mario Silveira (Universidad Nacional de Buenos Aires)

Dra. Silvia Simonassi (Universidad Nacional de Rosario)

Dra. Alicia Tapia (Universidad Nacional de Buenos Aires, Universidad Nacional de Luján)

Lic. Mónica P. Valentini (Universidad Nacional de Rosario)

Agrim. Benito Vicioso (Universidad Nacional de Rosario)

\section{Evaluaron este volumen}

Roberto Bárcena, María Teresa Boschin, Leonel Cabrera, Ulises Camino, María Rosa Carbonari, Carlos Ceruti, Horacio Chiavazza, Nicolás Ciarlo, Silvia Cornero, Eduardo Crivelli, Javier García Cano, Martín Gentinetta, María Laura Gili, Carlos Landa, Matilde Lanza, Melina Malandrino, Sebastián Pastor, Victoria Pedrotta, Josefina Piana,

Mercedes Podestá, Mariano Ramos, Daniel Schavelzon, Diana Tamburini, Mónica Therrien, Mónica Valentini y María Teresa Boschin

\section{Diseño y diagramación}

Eugenia Reboiro

(eugenia.reboiro@gmail.com)

\section{Curadoría}

Ana Rocchietti e Irene Dosztal

Foto de tapa: imagen del texto de Croce.

\section{Propietario responsable:}

Facultad de Humanidades y Artes, Universidad Nacional de Rosario Centro de Estudios de Arqueología Histórica

Entre Ríos 758. Rosario, provincia de Santa

Fe (2000). Argentina.

Telf.: +54 (0341) 4802670

E-mail: ceahunr@gmail.com

Decreto Ley 6422/57 de Publicaciones

Periódicas 


\section{Índice}

Editorial.

Arqueología histórica: programa de investigación y dimensiones epistemológicas...9 Ana María Rocchietti

De lozas, iglesias y machaqueños. Primeros pasos hacia una arqueología histórica en la cuenca norte del río desaguadero (La Paz, Bolivia).

Salvador Arano Romero

Identificación arqueológica de acciones militares en el campo de batalla de Cepeda, 1859.

Juan B. Leoni, Lucas H. Martínez, Cecilia Arias Morales, Daniela Cadenas,

Faustino Godoy, Mauro Ganem, María de la Paz Blanche y Héctor Meletta

Para una historia de la arqueología urbana en Buenos Aires (1848-1910) .59

Daniel Schávelzon y Francisco Girelli

Definiendo la cultura material colonial a partir de colecciones arqueológicas del Museo de La Plata.

Melina Bednarz, Julieta Penesis y Ana Igareta

La tangibilidad del conflicto: Arqueología del presente en las fronteras del norte santafesino....

Paula Del Río y Silvia Cornero

Arqueología histórica: evidencia material en el paisaje del establecimiento jesuita "La saladilla” (quebrada de Saladillo, La Rioja, Argentina). Juan Carlos Giuliano, Maira Ayelén Carrizo y María Soledad Gheggi

Graffiti ¿evidencia arqueológica o acto vandálico?. Camila Oliva

Arqueología histórica de los sistemas hidráulicos de la Hacienda

Jalpa de Cánovas, Guanajuato, México, y su relación con el sistema-mundo, Siglos XVIII-XIX

José Alberto Aguirre Anaya y Edgar Quispe Pastrana 
Paseo del bajo: una trinchera en la historia de Buenos Aires.................................143 Federico Martín Croce

Diferentes concepciones del patrimonio y su aplicación a la Casa Histórica de Tucumán también llamada Casa de la Independencia........................................155 Guillermo Etchevers

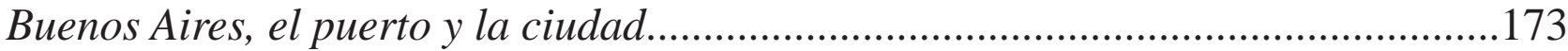
Mónica P. Valentini y Javier García Cano 


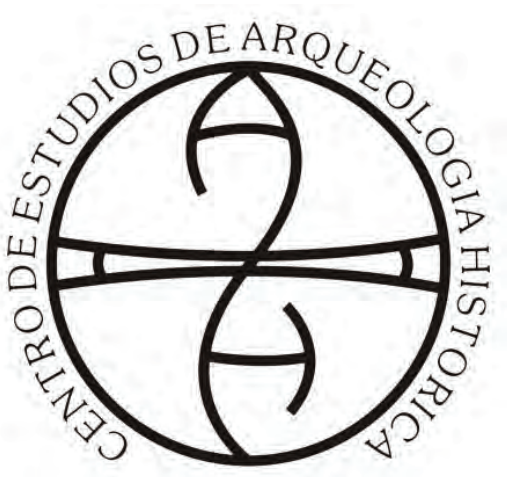

Centro de Estudios de Arqueología Histórica

Universidad Nacional de Rosario
Teoría y Práctica de la Arqueología Histórica

Latinoamericana | Año VIII. Vol. 8 | 2019

Revista del Centro de Estudios de Arqueología

Histórica, Facultad de Humanidades y Artes,

Universidad Nacional de Rosario

https://teoriaypracticaah.unr.edu.ar/index.php/index ceahunr@gmail.com

ISSN en línea: 2591-2801

ISSN versión impresa: 2250-866X

\title{
De lozas, iglesias y machaqueños. Primeros pasos hacia UNA ARQUEOLOGÍA HISTÓRICA EN LA CUENCA NORTE DEL RÍO DESAGUADERO (LA PAZ, BOLIVIA)
}

\author{
Salvador Arano Romero*
}

\begin{abstract}
Resumen
La arqueología de Jesús de Machaca se caracteriza por el aporte que ha hecho al esclarecimiento de las sociedades prehispánicas, sin embargo, no ha mostrado avances sustanciales en los denominados períodos históricos (Colonial y Republicano). Por ello es que a partir del año 2012 venimos realizando trabajos de registro tomando en cuenta componentes arqueológicos post-conquista española, y así dar luces sobre la materialidad de esos períodos. En el presente trabajo nos enfocaremos en ahondar sobre dos componentes materiales importantes: la cerámica y las iglesias. Más allá de sus características formales, se pretende establecer la relación de estos objetos con los sujetos que interactuaron con ellos, pero sobre todo enfatizando en los pobladores locales, de los cuales en muchos casos no quedan registros históricos y que jugaron un papel importante en Jesús de Machaca. De este modo veremos a la cerámica como expresión del acceso diferenciado de consumo entre los distintos personajes de la comunidad machaqueña, y las iglesias como expresión de las relaciones de poder establecidas por los curas doctrineros y la elite cacical de la marka.
\end{abstract}

Palabras clave: Jesús de Machaca, mayólica, iglesias, colonial, republicano

\begin{abstract}
The archeology of Jesús de Machaca is characterized by the contribution about pre-hispanic societies, however, has not shown substantial progress in the historical periods (Colonial and Republican). That's why, starting in 2012, we have carried out registration works taking into account Spanish post-conquest archaeological components, and thus shed light on the materiality of those periods. In this paper we will focus on delving into two important material components: ceramics and churches. Beyond its formal characteristics, it is intended to establish the relationship of these objects with the subjects who interacted with them, but especially emphasizing the local inhabitants, that in many cases there are no mentioned in
\end{abstract}

* Unidad Ejecutora en Ciencias Sociales Regionales y Humanidades. Consejo Nacional de Investigaciones Científicas y Técnicas 
Teoría y Práctica de la Arqueología Histórica Latinoamericana | Año VIII. Vol. 8 | 2019

ISSN en línea: 2591-2801 | ISSN versión impresa: 2250-866X

historical records and that played an important role in Jesús deMachaca. In this way we will see ceramics as an expression of differentiated access to consumption among the different characters of the Machaca community, and the churches as an expression of the power relations established by the priests and the cacicalelite of the marka.

Keywords: Jesús de Machaca, majolica, churches, colonial, republican

\section{Introducción}

La historia de Jesús de Machaca en el altiplano boliviano ha sido reflejada desde muchas perspectivas investigativas, sobre todo la historia y la sociología, denotando su particularidad como foco de liderazgo indígena en Bolivia (Albó, 1972, 1996; Barnadas, 1975; Rivera Cusicanqui, 1978; Choque, 1986, 1988, 1990; Choque y Ticona, 1996; Ticona, 1990, 1991, 1993; Ticona y Albó, 1997; Morrone,2010a, 2013). Y en apoyo a estos estudios es que en los últimos años los estudios arqueológicos han ido cobrando mucha fuerza para recalcar la importancia de esta región (Arano, 2018; Janusek, 2013; Pérez, 2014), tanto en la época prehispánica, como en las etapas colonial, republicana y contemporánea, siendo estas últimas un poco olvidadas por los arqueólogos.

De igual forma, en la última década, ha sido decisiva en la arqueología boliviana el interés por los períodos históricos (colonial y republicano sobre todo). Muchos de ellos han aportado datos sobre la minería (Cruz y Téreygeol, 2018; Ulloa, 2010; Van Buren y Cohen, 2010), arquitectura habitacional (De la Rocha, 2013; Torrico, 2013) y religiosa (Cayo, 2010; Rendón, Fredericksen, Salvatierra, Méncias y Trigo, 2007), análisis de cerámica importada y local (Alejo, 2013; Antezana, 2016; Mencias, 2009), y recintos militares (Bejarano, 2011). Estos estudios han logrado esclarecer muchas dudas sobre la materialidad en los momentos post-conquista, sin embargo, aún queda mucho por dilucidar, sobre todo en áreas actualmente rurales del país, que guardan una gran cantidad de sitios correspondientes a estos períodos.

Con los trabajos realizados dentro del Proyecto Arqueológico Tambo Jesús de Machaca (PATJM) ${ }^{1}$ y el Proyecto Catastro Arqueológico del Municipio de Jesús de Machaca (PCAJM)², logramos registrar una gran variedad de sitios pertenecientes a los períodos Colonial y Republicano y que evidencian la importancia de la región en el marco de la conquista española y la conformación de la república. Aunque los sitios identificados no son muchos, estos trabajos marcan un antecedente importante para los estudios de arqueología histórica en Jesús de Machaca.

En el presente trabajo nos enfocaremos mostrar dos elementos fundamentales para la identificación de sitios históricos. En primera instancia veremos la diversidad del material cerámico que nos da cuenta de la importancia del Tambo de Jesús de Machaca (actual pueblo de Jesús de Machaca) en la región. Y como segundo aspecto orientaremos el trabajo en ver aquellas edificaciones católicas presentesen todo el municipio, donde la mayoría se encuentran abandonadas y en un mal estado de conservación.

\section{El área de estudio}

Jesús de Machaca se encuentra en el municipio homónimo, en la Provincia Ingavi del Departamento de La Paz en Bolivia. Se emplaza en una planicie a las faldas del extremo suroeste de la serranía de Jesús de Machaca que divide dicho municipio con el de Tiahuanaco (Grupo Alfa, 2014; Instituto Geográfico Militar, 2012), formado así dos ambientes ecológicos: el alto andino y la puna, los cuales son denominados por los pobladores locales como cordillera y pampa respectivamente. El municipio está dividido 
Teoría y Práctica de la Arqueología Histórica Latinoamericana | Año VIII. Vol. 8 | 2019

ISSN en línea: 2591-2801 | ISSN versión impresa: 2250-866X

políticamente en dos parcialidades, la Marka de Ayllus y Comunidades Originarias de Jesús de Machaca (MACOJMA) y la Marka de Ayllus y Comunidades de AraxSuxta (MACOAS), y a su vez el territorio municipal se conforma de 26 Ayllus y 76 comunidades (Albo, 2012, p. 28; Jordán et al., 2011, p. 25).

\section{Antecedentes}

Parte de la investigación arqueológica y sus resultados han desentrañado aspectos como la distribución espacial, procesos de ocupación, producción económica y en especial el análisis de la cerámica, que es un referente en el altiplano para los períodos prehispánicos. Sin embargo, a partir de la incursión de los españoles alrededor de 1547 poco se ha debatido sobre este componente cultural, y es por eso que este trabajo pretende reflejar, no solo los componentes materiales registrados, sino la importancia de Jesús de Machaca en el plano social.

Gran parte de los trabajos arqueológicos(Albarracín, 1996; Janusek, 2003; Arano, 2015a; Pérez 2017), a partir de los análisis cerámicos, para los primeros años de la colonia han logrado identificar un estilo denominado en la región como Pacajes Tardío o Pacajes Colonial (1540 - 1600 d.C.). Aunque este período se enmarca dentro de los primeros años de la colonia, estilísticamente hablando, solo se toma en cuenta el material cerámico para definirlo, y la mayoría de los estudios arqueológicos no ahondan más sobre este momento de transición. En un trabajo anterior (Arano, 2018) identificamos, a partir del registro material, las posibles relaciones de poder que existieron durante el 1470 al 1600 en el Tambo de Jesús de Machaca, tomando en cuenta el material cerámico, la arquitectura y el paisaje.A partir de estas investigaciones, en el marco del PCAJM nos propusimos incluir en el registro general de sitios aquellos componentes que puedan ser asociados dentro de los períodos históricos, entre los cuales pudimos identificar acumulaciones de materiales artefactuales, construcciones religiosas, sitios habitacionales, sitios de producción y haciendas (Arano, 2017).

Para este trabajo también tomaremos en cuenta sitios registrados por otros proyectos, sin embargo, la información de estos sitios es muy escueta, y la mayoría son asociados con el Pacajes Colonial. En el Proyecto Arqueológico Jacha Machaca, dirigido por Janusek, se presentan los resultados de las prospecciones realizadas en las comunidades de Khonkho LiquiLiqui, Khonkho Milluni,Sullkatiti Titiri y Cuypa España, donde se identificaron 21 sitios correspondientes a la época colonial (Lemuz, 2006), sin embargo, no se presenta mayor información sobre su ubicación y los materiales asociados. Por otro lado los trabajos realizados por Pérez $(2014,2017)$ dan cuenta que el sitio de Iruhito también registraría asentamientos pertenecientes a los primero años de la colonia, determinados a partir del estilo Pacajes Colonial.

Como podemos observar, los trabajos son muy escasos y solamente responden a trabajos dirigidos a estudios prehispánicos, y no así a investigaciones dedicadas a los períodos históricos (Tabla 1). En este sentido, y basándonos en nuestros trabajos anteriores (Arano 2017, 2018), hemos logrado sistematizar los datos obtenidos y tener una visión preliminar de los sitios históricos en el territorio municipal (Figura 1). Sin embargo, también buscamos abordar la importancia del estudio de sitios históricos en el Municipio de Jesús de Machaca, y de igual forma el potencial que tienen los mismos en la reconstrucción del pasado de los pueblos locales y que su historia no solo va ligada a lo prehispánico, y que responde a una construcción social colonial y mucho más compleja. Por ello creemos que no solamente es un aporte a la academia, es más bien una herramienta práctica para los comunarios de las distintas comunidades y ayllus para que conozcan su historia y vean la importancia de toda la materialidad del pasado. 
Tabla 1. Sitios post-conquista de Jesús de Machaca

\begin{tabular}{ll}
\hline Período & Número de Sitios \\
\hline Pacajes (Fase Pacajes Tardío) & 78 \\
\hline Colonial & 22 \\
\hline Republicano & 37 \\
\hline
\end{tabular}

Relación de sitios arqueológicos de períodos históricos en el Municipio de Jesús de Machaca. En base a Arano, 2017, 2018; Lemuz, 2006; Pérez, 2014).

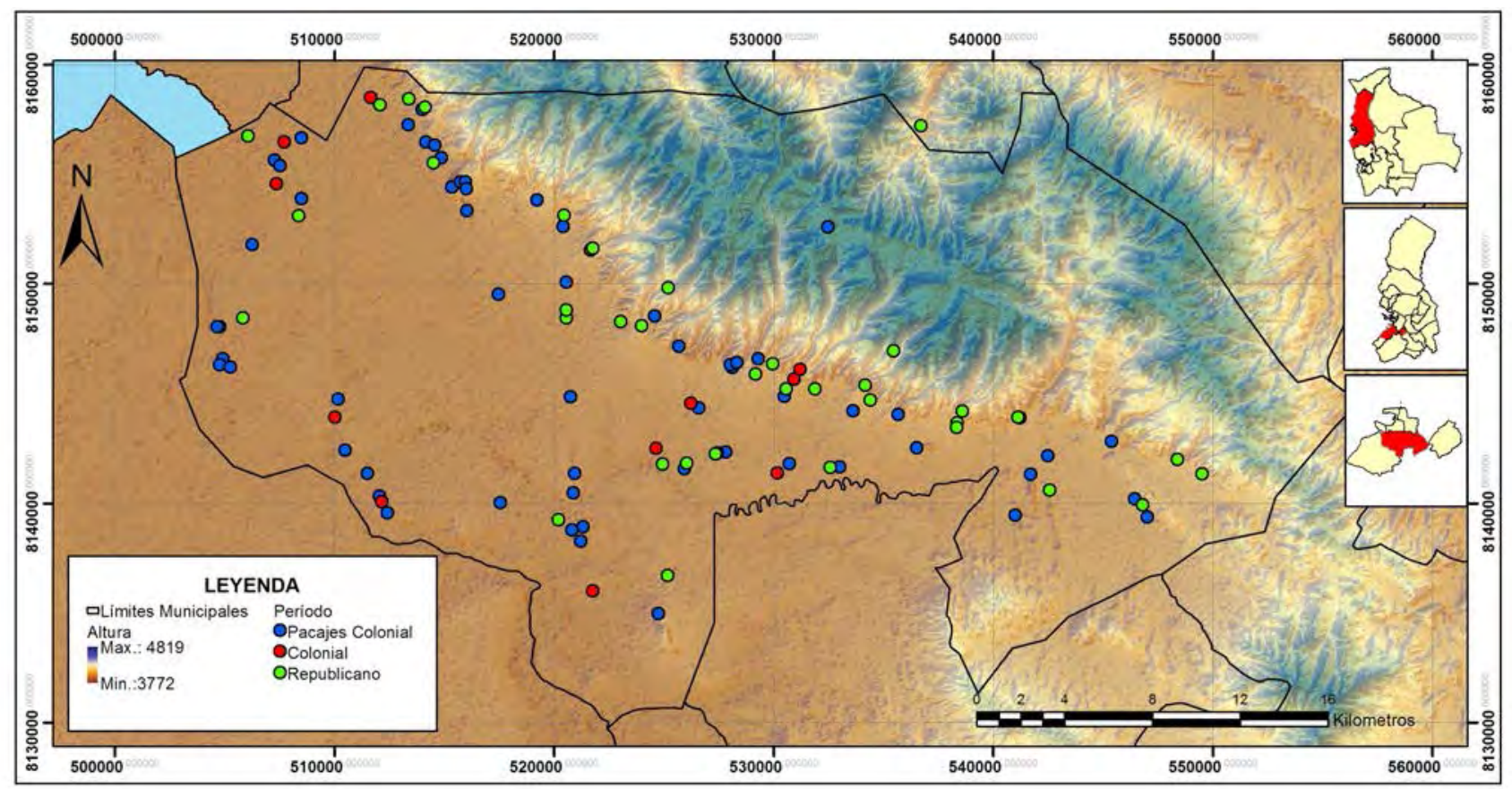

Figura 1. Ubicación de los sitios coloniales y republicanos en el Municipio de Jesús de Machaca. Elaboración propia en base a Arano (2017, 2018), Lemuz (2006) y Pérez (2014).

\section{Metodología}

En primera instancia debemos mencionar que los trabajos arqueológicos aquí presentados responden a los resultados de investigación del PATJM y el PCAJM, que se encargaron de hacer los registros pertinentes. Para la determinación cronológica de los sitios nos basamos netamente en los atributos cerámicos y arquitectónicos como componentes diagnósticos.

Los resultados en el Tambo de Jesús de Machaca fueron obtenidos a partir de prospecciones intrasitio y la apertura de cuatro unidades de excavación en el sitio PATJM-001 (Arano, 2018). El material principal para la creación de tipologías fue la cerámica, donde se pudieron identificar una gran variedad de estilos, principalmente en los trabajos de prospección. Pero en la excavación solo se pudo registrar 
elementos filiados al estilo Pacajes Colonial, relacionados a los fragmentos Pacajes Inka dentro de una qollqa (almacenes) y basurales cercanos. Como una hipótesis se establece que los almacenes no solo fueron reocupados, posiblemente haya existido nuevas construcciones luego de la llegada de los españoles.

Por otro lado, dentro del PCAJM, los resultados utilizados en este trabajo responden al registro de sitios arqueológicos en todo el municipio (Arano, 2017), a partir del trabajo en conjunto con los pobladores locales, quienes coadyuvaron con la identificación de los sitios (Portugal, 2017). Esta estrategia de prospección, no solamente resulta eficaz e innovadora, también aporta mucho en el sentido de la importancia de los sitios para los pobladores locales, su percepción sobre su significado, y la asociación entre sitios, que en muchos casos no es tomado en cuenta en las estrategia convencionales.

\section{La cerámica histórica de Jesús de Machaca}

A partir del análisis de material cerámico del PATJM (Arano, 2015a) pudimos identificar que la comunidad de Jesús de Machaca fue ocupada luego de la llegada del Inka a la región (1470 aproximadamente), y a partir de ese momento la ocupación fue continua hasta la fecha. Sin embargo, en estos trabajos nos enfocamos específicamente en la cerámica de períodos prehispánicos y aquellos ceramios de los primeros años de la colonia, especialmente del estilo Pacajes Colonial. En las prospecciones realizadas bajo el PATJM se evidenció una gran cantidad de material cerámico histórico donde preliminarmente se pudo identificar una variedad de tipos, los cuales debían ser contrastados con más investigaciones (Tabla 2).

Tabla 2. Tipos cerámicos post-conquista española.

\begin{tabular}{llll}
\hline Tipo & Fragmentos & Tipo & Fragmentos \\
\hline Pacajes Colonial & 292 & Mayólica Local & 12 \\
\hline Colonial (roja y vidriada) & 14 & Escuela de Puno & 38 \\
\hline Mayólica Contisuyo & 27 & Porcelana & 2 \\
\hline Mayólica Española & 5 & Republicana/Contemporánea & 80 \\
\hline
\end{tabular}

Cantidad de fragmentos por cada tipo histórico identificado. Elaborado en base a Arano (2015b).

Podemos ver que existe una clara diferencia en la cantidad de los ceramios de inicios de la colonial con respecto a los otros tipos históricos, esto debido a que los artesanos locales pertenecientes al grupo Pacajes continuaron con la producción de cerámica de la misma forma que la venían haciendo desde el Intermedio Tardío, pero incorporando nuevos motivos y formas. Si bien la cantidad de fragmentos no es muy alta, la presencia de algunos tipos cerámicos es un indicador acerca de la importancia del sitio durante la época colonial y republicana (Figura 2), sobre todo con la presencia de mayólica española y porcelana. Bajo el PCAJM al momento de realizar la identificación de los materiales recolectados, solamente se procedió a diferenciar los tipos Pacajes Tardío, Colonial y Republicano, sin entrar en tipos específicos. De todas formas, haciendo un análisis macroscópico se pudo identificar la presencia de ceramios correspondientes a los tipos Mayólica Contisuyo, Mayólica Local y a la Escuela de Puno.

Los fragmentos correspondientes a materiales foráneos son muy escasos, pero su presencia nos abre el panorama que no debemos invisibilizar su incidencia. Al ser un tambo Inka, en los años posteriores a 
la llegada de los españoles a la región (1540 aproximadamente), Cristóbal Vaca de Castro (1989 [1543]) realiza el ordenamiento de tambos en todo el Tawantinsuyo con el fin deestablecer sectores bisagra entre las distintas regiones productivas. En este sentido, toda el área circunlacustredel Titicaca juega un rol fundamental al ser un nexo entre Lima y Potosí, y como sector de acceso directo a los yungas (Morrone, 2013). La existencia de porcelana y mayólica española, es un demarcador importante para identificar los grupos sociales que pudieron vivir en la comunidad, es decir,personas que quisieran ostentar unestatus elevado.

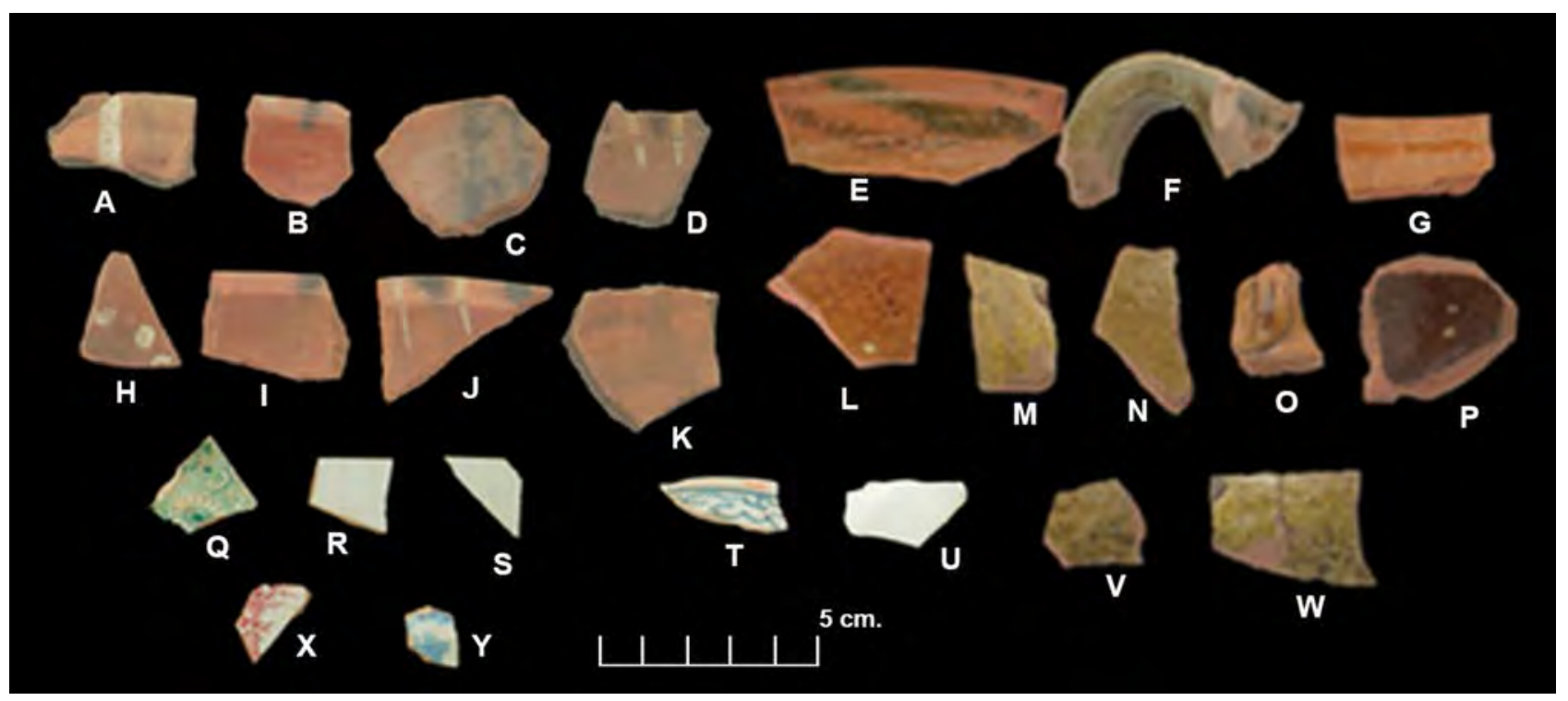

Figura 2. Tipos cerámicos históricos identificados en el Sitio PATJM-001. Pacajes Colonial (A,B,C,D,H,I,J,K), Colonial (P), Mayólica Española (Q,R,S,X,Y), Porcelana (T,U), Escuela de Puno (F,M,N,Q,V,W), Republicano (E,G,L). Fotografía de autor.

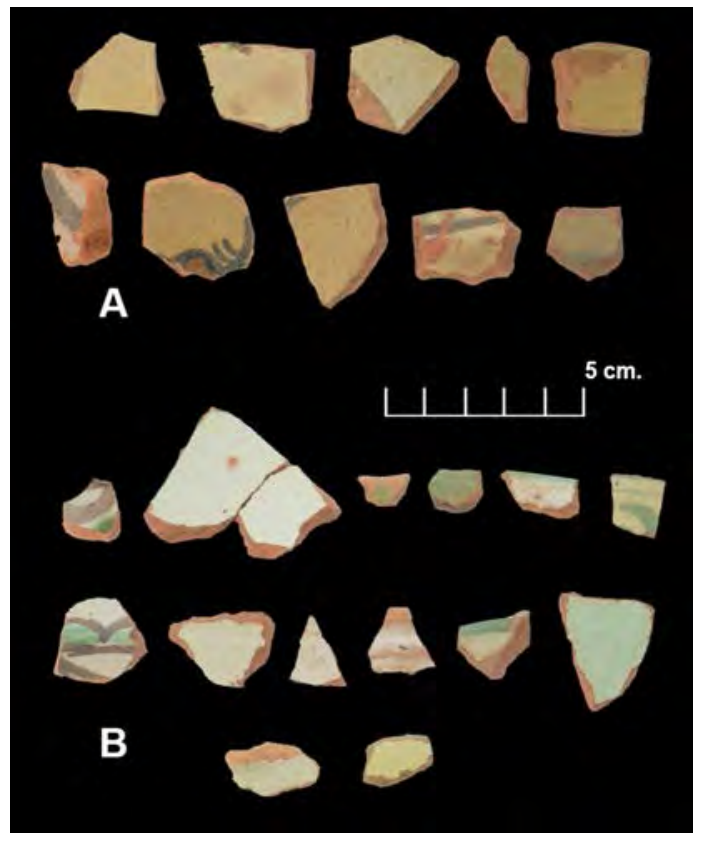

Sin embargo, uno de los componentes en los que queremos hacer mayor hincapié, es en aquellas que parecieran ser de factura local (el tipo mayólicas locales). Haciendo un análisis macroscópico de las pastas y los esmaltados, existe una clara división entre dos tipos de mayólicas, por un lado, aquellas denominadas Contisuyo, contra otras que, si bien imitan los motivos y colores en el acabado, no guardan una semejanza con las primeras (Figura 3).

Figura 3. Componentes cerámicos pertenecientes al tipo Mayólica; Local (conjunto A) y ContisuyoMás allá Polícromo (conjunto B). Fotografía del autor. 
Teoría y Práctica de la Arqueología Histórica Latinoamericana | Año VIII. Vol. 8 | 2019

ISSN en línea: 2591-2801 | ISSN versión impresa: 2250-866X

Este tipo cerámico Mayólica Contisuyofue definido en primera instancia por Rice (1997) en los trabajos realizados en Moquegua, el autor hace una división de este tipo en dos estilos, el Más Allá Polícromo y el EscapalateAmarilllo Polícromo (p. 175), siendo el primero el correspondiente a nuestro conjunto, porque presenta un esmalte color crema y blanquecino con decoración en tonos verdes, cafés y violáceos con motivos florales en su mayoría, y que es reportada en algunos lugares de Bolivia (Antezana, 2015; Ulloa, 20104; Villanueva 2014). De igual forma, siguiendo los trabajos de Rice (1997), Tschopik (1950) y Jamieson (2001) ${ }^{5}$, es posible que uno de los centros alfareros más importantes de producción de este tipo de mayólica sean la comunidad de Pupuja (Puno), situándose aproximadamente a 300 km de Jesús de Machaca. Si bien es una distancia considerable, el tráfico y circulación de este material se dio en gran parte del área andina llegando hasta Mendoza (Schávelzon, 2001, p. 78), siendo parte toda esta región de una de las esferas de producción de mayólica que identifican Rice y Natt (2013), y que luego es apoyada por trabajos petrográficos en el norte de Perú (Kelloway et. al., 2018).

Sin embargo, en el tambo de Jesús de Machaca logramos identificar una cerámica esmaltada muy similar con algunas variaciones sustanciales, sobre todo en la pasta (con granos más gruesos) y en la calidad del esmaltado, siendo este opaco y no muy pulcro a la hora de su aplicación. Esto nos haría inferir en dos hipótesis, (1) que el material no está siendo elaborado en los principales centros de producción, o (2) que corresponde a material elaborado por aprendices y que de igual forma circuló en las regiones aledañas a los centros productivos. Si bien no contamos con los registros de centros alfareros coloniales en la región, no sería el primer caso donde se propone que existía una producción de lozas a nivel local o micro-regional (Antezana, 2016; Van Buren, 1999). Por lo tanto, nos animamos a decir que esos fragmentos (Figura 3, Conjunto A) corresponden a ceramios fabricados en Jesús de Machaca, y fueron imitados para que circulen localmente.

En síntesis, estaríamos hablando de diferentes tipos de acceso a los materiales, por un lado, un grupo que estaría consumiendo ceramios españoles (mayólicas y porcelanas), otro, o tal vez el mismo grupo, que consume aquella mayólica de tradición andina (Contisuyo más allá Polícromo), y un último grupo que tiene acceso, y fabrica, un material de factura local (Mayólica Contisuyo Local) y la cerámica roja o vidriada. Esta “clase alta” estaría conformada posiblemente por aquella elite cacical que se acentúa a partir del Siglo XVII (Morrone, 2010a) y/o por los curas doctrineros de la región (Morrone, 2010b). Este acceso a diferentes tipos cerámicos puede ser producto del acceso a recursos económicos y la capacidad de poder obtener ciertos bienes de prestigio. Por ello no debemos dejar de lado que los bienes más ostentosos siempre son copiados para el acceso público, en una especie de mímesis del objeto, que en nuestro contexto son denominados como truchos ${ }^{6}$.

\section{La dimensión material del Catolicismo}

Uno de los objetivos del PCAJM fue incluir en su registro de sitios arqueológicos a las iglesias y a los objetos que se asocian a las mismas. En total se lograron identificar 7 iglesias coloniales, principalmente de los siglos XVIII y XIX, y 8 iglesias republicanas (Figura 4). De todas estas iglesias solamente cuatro siguen funcionando actualmente, y de estas una tiene un uso constante, mientras que las otras tres son de uso periódico. La única iglesia de constante funcionamiento es el Templo de Jesús de Machaca, que data de 1706, terminada de construir bajo el mandato del entonces cacique José Guarachi (Arano, 2017; Choque, 1994; Morrone2010b). Las otras tres iglesias son las de Yahuriri San Juan, Cuipa España y Achuma Santa Ana; siendo estas tres utilizadas esporádicamente para misas de mes, bautizos y matrimonios.

De lozas, iglesias y machaqueños...

S. ARANO ROMERO 


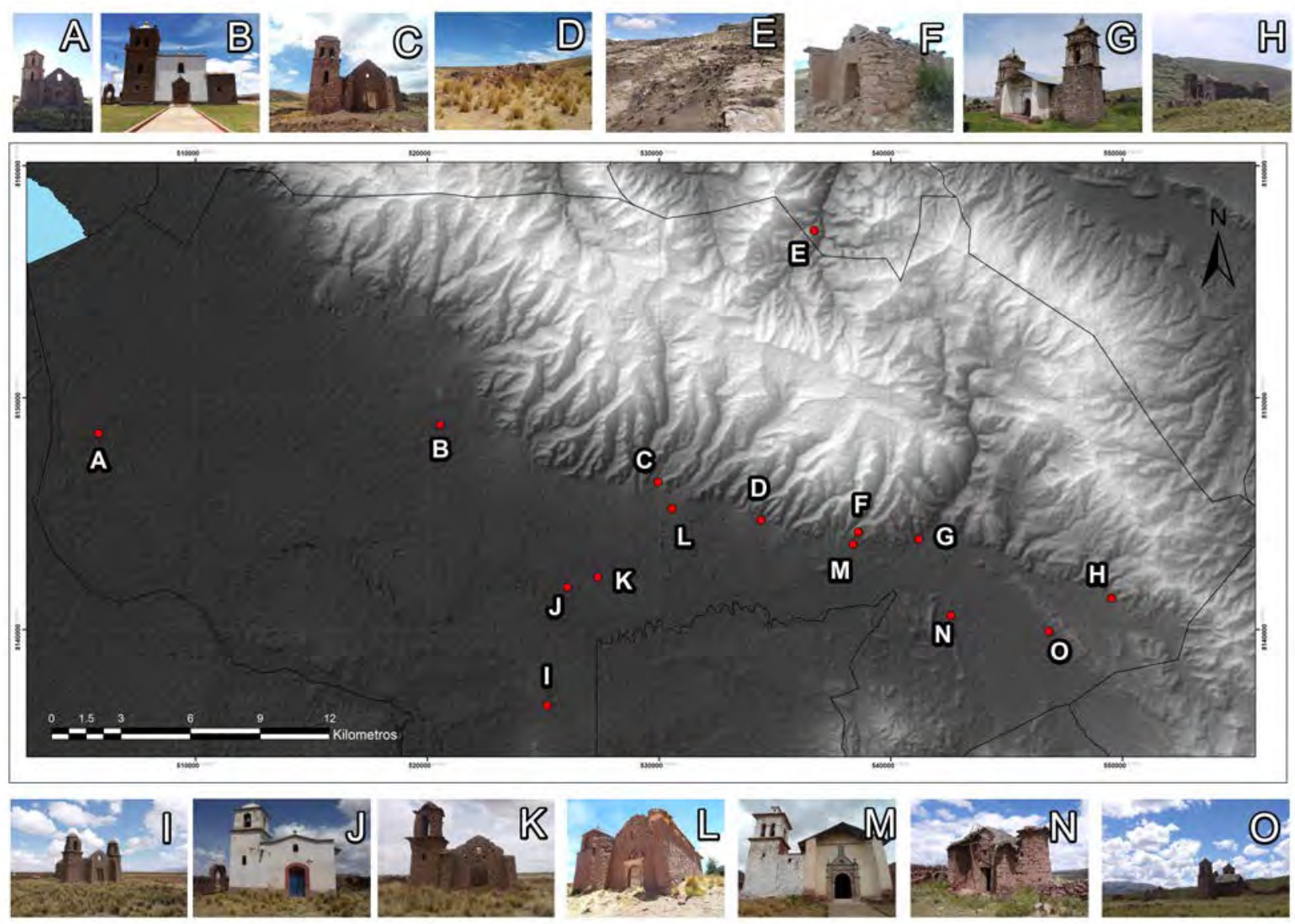

Figura 4. Ubicación de las iglesias registradas en el PCAJM. Elaboración propia en base a Arano, 2017. 
Teoría y Práctica de la Arqueología Histórica Latinoamericana | Año VIII. Vol. 8 | 2019

ISSN en línea: 2591-2801 | ISSN versión impresa: 2250-866X

Tabla 3. Iglesias del Municipio de Jesús de Machaca

\begin{tabular}{|c|c|c|c|c|c|}
\hline & SITIO & AYLLU & COMUNIDAD & NOMBRE & $\begin{array}{l}\text { ORIENTACIÓN } \\
\text { DEL ALTAR }\end{array}$ \\
\hline A & $\begin{array}{l}\text { PCAJM- } \\
0019\end{array}$ & Jancoaque Bajo & Jancoaque Tana & $\begin{array}{l}\text { Capilla Virgen } \\
\text { del Carmen }\end{array}$ & Sureste \\
\hline B & $\begin{array}{l}\text { PCAJM- } \\
0070\end{array}$ & Jesús de Machaca & Jesús de Machaca & $\begin{array}{l}\text { Templo de Jesús } \\
\text { de Machaca }\end{array}$ & Sureste \\
\hline $\mathrm{C}$ & $\begin{array}{l}\text { PCAJM- } \\
0111\end{array}$ & SullcatitiLahuacollo & $\begin{array}{l}\text { SullcatitiLahua- } \\
\text { collo }\end{array}$ & Iglesia San José & Suroeste \\
\hline $\mathbf{D}$ & $\begin{array}{l}\text { PCAJM- } \\
0084\end{array}$ & $\begin{array}{l}\text { Khonkho Lli- } \\
\text { quilliqui }\end{array}$ & $\begin{array}{l}\text { Khonkho Lli- } \\
\text { quilliqui }\end{array}$ & - & Sureste \\
\hline $\mathbf{E}$ & $\begin{array}{l}\text { PCAJM- } \\
0088\end{array}$ & SullcatitiTitiri & SullcatitiTitiri & T’ijiWaranka & - \\
\hline $\mathbf{F}$ & $\begin{array}{l}\text { PCAJM- } \\
0140\end{array}$ & Cuipa España & Cuipa España & Cruz Kunka & Sur \\
\hline G & $\begin{array}{l}\text { PCAJM- } \\
0167\end{array}$ & Achuma & $\begin{array}{l}\text { Achuma Santa } \\
\text { Ana }\end{array}$ & - & Este \\
\hline $\mathbf{H}$ & $\begin{array}{l}\text { PCAJM- } \\
0161\end{array}$ & Jilatiti Seco Pacuni & Seco Pacuni & $\begin{array}{l}\text { Iglesia de Pa- } \\
\text { cuni }\end{array}$ & Noroeste \\
\hline I & $\begin{array}{l}\text { PCAJM- } \\
0005\end{array}$ & - & - & - & Este \\
\hline $\mathbf{J}$ & $\begin{array}{l}\text { PCAJM- } \\
0044\end{array}$ & Yauriri San Juan & Yauriri San Juan & - & Este \\
\hline $\mathbf{K}$ & $\begin{array}{l}\text { PCAJM- } \\
0045\end{array}$ & Yauriri San Juan? & Yauriri San Juan? & - & Sur \\
\hline $\mathbf{L}$ & $\begin{array}{l}\text { PCAJM- } \\
0103\end{array}$ & SullcatitiTitiri & SullcatitiTitiri & - & Suroeste \\
\hline $\mathbf{M}$ & $\begin{array}{l}\text { PCAJM- } \\
0136\end{array}$ & Cuipa España & Cuipa España & - & Sureste \\
\hline $\mathbf{N}$ & $\begin{array}{l}\text { PCAJM- } \\
0184\end{array}$ & CuipaCahuayo & $\begin{array}{l}\text { CuipaCahuayo } \\
\text { “A” }\end{array}$ & $\begin{array}{l}\text { Iglesia } \\
\text { Magdalena }\end{array}$ & Noreste \\
\hline $\mathbf{O}$ & $\begin{array}{l}\text { PCAJM- } \\
0192\end{array}$ & Sullcatiti Arriba & Liríoni & $\begin{array}{l}\text { Iglesia de Lirío- } \\
\text { ni }\end{array}$ & Noroeste \\
\hline
\end{tabular}

Listado de iglesias con respecto a la Figura 4. Elaborado en base a Arano, 2017.

A excepción del Templo de Jesús de Machaca, que presenta una planta de crucero, las demás iglesias o capillas presentan una planta rectangular que tiene entre una o dos torres campanario (ver Figura 4). Los materiales constructivos de las naves principales varían entre adobe (8 iglesias) y bloques de piedra (6 iglesias), y una de la cual no existen vestigios arquitectónicos pero que forma parte de los relatos orales y presenta algunos objetos que podrían corroborar su existencia, hablamos de la iglesia de T’ijiWaranka (Arano, 2017, p. 88). Las torres o campanarios, de igual forma varían entre adobe y piedra como material de construcción, contando con tres casos interesantes.La Capilla Virgen del Camen en Jancoaque Tana, que presenta una torre de planta octogonal elaborada a base de ladrillos, producto de las 
reconstrucciones; y las Iglesia San José en Sullca Titi Llaukakollo yde Achuma Santa Ana, que presenta un campanario edificado a partir de bloques de arenisca, con la particularidad que tienen algunos bloques de cobre (Figura 5).

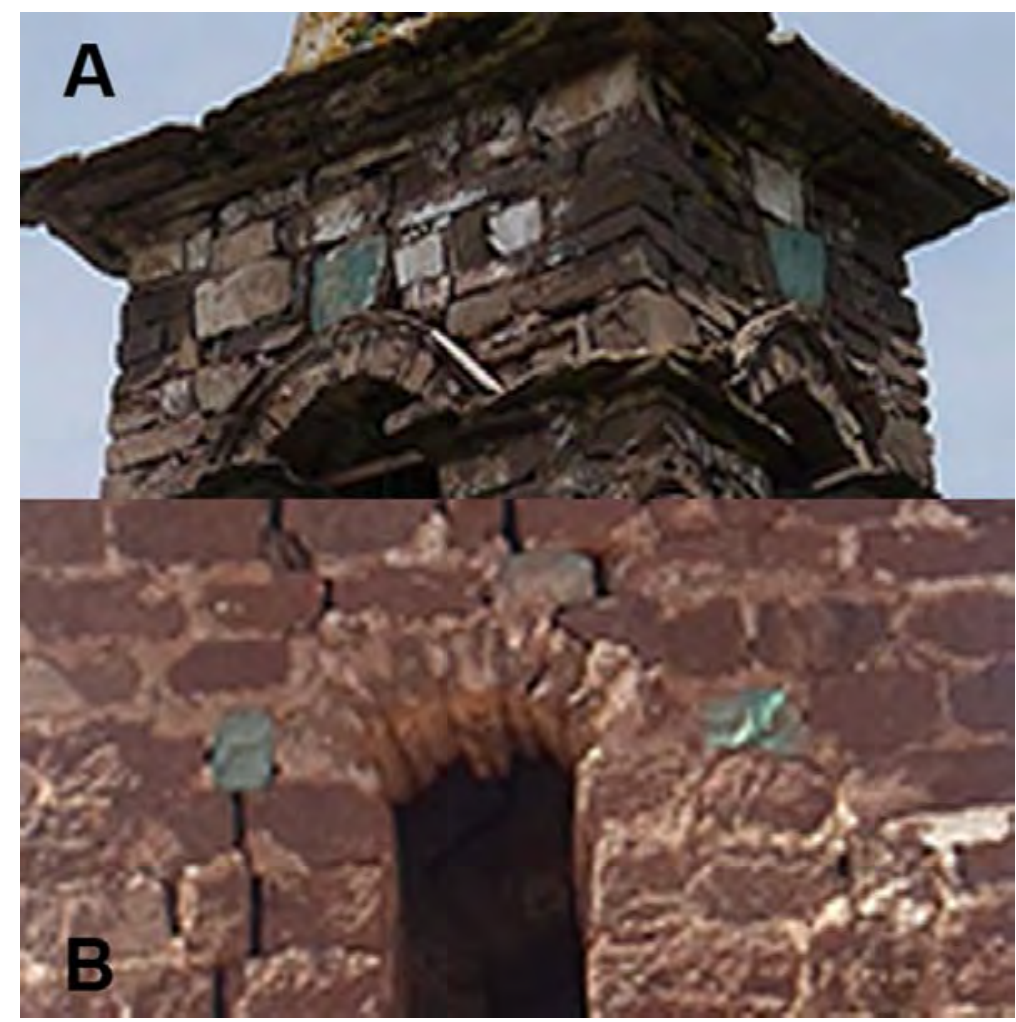

Figura 5. Detalle de los bloques de cobres utilizados en la edificación de los campanarios de (A) Achuma Santa Ana y (B) San José. En base a Arano (2017).

Entre los materiales asociados a estas iglesias resaltan dos casos. La iglesia de Yahuriri San Juan presenta varios artefactos utilizados en las misas tales como retablos, misales (S. XVIII), portavelas y túnicas. La iglesia de T'ijiWaranka, la cual no presenta la edificación, evidencia tres artefactos elaborados sobre bloques líticos, estos son conocidos cómo la cruz, el lavatorio y la Virgen. Esta última es un bloque de roca arenisca tallada con rasgos antropomorfos (Figura 6), en ella sobresale su rostro, con características muy similares a los detalles que adornan las iglesias del barroco-mestizo del siglo XVII y XVIII (Samanez, 2011), sobre todo las denominadas sirenas andinas plasmadas en los pórticos de las iglesias alrededor del lago Titicaca (Gisbert, 2004). 


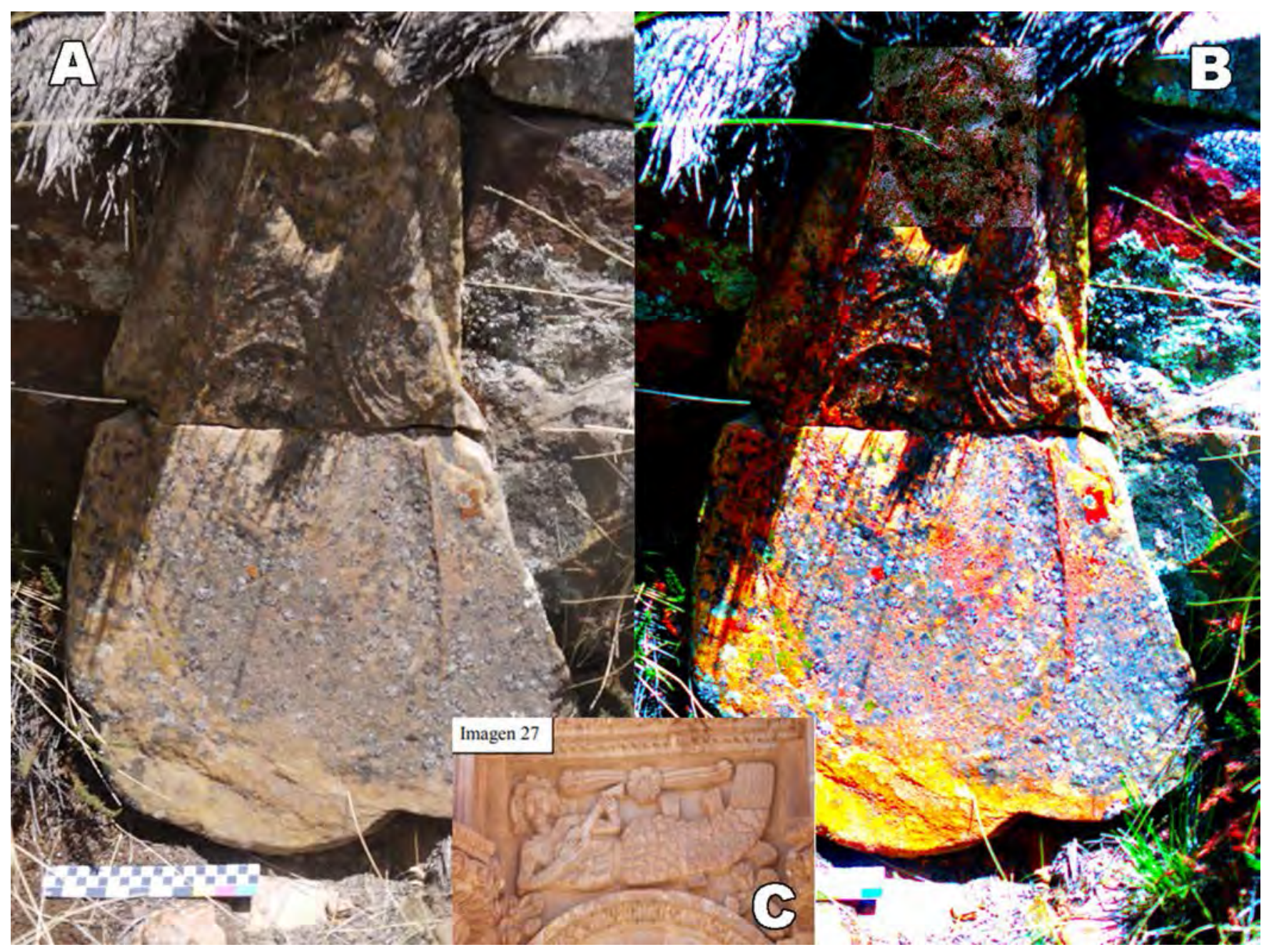

Figura 6. (A) Imagen de la "Virgen" de la Iglesia de T'ijiWaranka (Arano, 2017, p. 189, Figura 4.11). (B) Imagen modificada de la "Virgen" en el software D-Stretch (Copyright $\mathbb{C}$, Jon Harman, http://www. dstretch.com/) con filtros LDS (Cuerpo) y YYE (Rostro). (C). Sirena de la fachada de la Catedral de Puno (Benavente, 2018, p. 116, Imagen 27).

De acuerdo a los datos proporcionados por Morrone (2010b), el actual Templo de Jesús de Machaca se encargó, durante el siglo XVII, de oficiar los bautismos de todos los ayllus de la región. Esta centralidad, auspiciada por los Fernandez Guarachi ${ }^{7}$, es posible que se haya mantenido hasta el siglo XVIII o principios del XIX, momento donde comienzan a edificarse estas "nuevas" capillas, casualmente cerca de las capitales de algunos de los ayllus originarios ${ }^{8}$. Esta descentralización que hace el clero puede responder a que la población en cada ayllu esté aumentando, o a factores más logísticos que requieren de la presencia del cura y una materialización de la religión en cada sector a modo de relaciones de poder (Foucault, 1976).

En este sentido, y trazando líneas investigativas a futuro, debemos pensar que al igual que la cerámica, las iglesias también fueron construidas por los machaqueños, por lo tanto siguieron algunas lógicas 
locales para su establecimiento. En la Tabla 3 podemos observar que existe una variedad con respecto a la orientación de los altares de las iglesias, esto puede estar condicionando una intencionalidad de los constructores para que el lugar donde va el Santo tenga relación con otro referente en el paisaje. La relación entre las iglesias y/o acontecimientos cristianos con el paisaje ha sido trabajada en diferentes partes de Europa (Gangui, Gonzáles, Perera y Belmonte, 2016; Gonzales-García, 2015) y en Latinoamérica (Ganqui, Gillén y Pereira, 2016; Zimbrón y Moyano, 2015). Por lo tanto, consideramos oportuno empezar una línea investigativa sobre este aspecto en trabajos futuros. Por el momento, gracias a la configuración geográfica de la región, podríamos hipotetizar sobre una relación de las iglesias con los cerros o wak'as que existen en Jesús de Machaca, pero no debemos dejar de lado el factor astronómico.

\section{Reflexiones y consideraciones finales}

Con este trabajo tratamos de dar a la luz la importancia y gran potencial de los estudios arqueológicos a nivel histórico en la región de Jesús de Machaca. Anteriormente los estudios solo se focalizaban en períodos prehispánicos, tomando poca importancia en los primeros años de la colonia. Sin embargo, con nuestros trabajos preliminares logramos identificar sitios históricos que pueden ayudar a comprender de mejor forma los procesos sociales de la región luego de la llegada de los españoles.

Con la evidencia que presentamos, no solo pretendemos mostrar la existencia de una tradición alfarera en la región, si no que esta producción e importación de ceramios denota una importancia sobre el uso diferenciado que pudo haber existido, el cual no solo se trata de pequeños detalles estilísticos, si no el uso de enceres que han sido clasificados dentro de un grupo perteneciente a la elite de las diferentes etapas históricas. Sin embargo, debemos tomar en cuenta la realización de estudios petrográficos a futuro para establecer de forma concreta la procedencia de la Mayólica Contisuyo Local.

La presencia de la iglesia católica fue importante en la región, sobre todo gracias a los lazos establecidos con losFernández Guarachi. Esta popularización de la fe hizo que a partir del siglo XVIII se comenzaran a construir otras capillas en los diferentes ayllus de Jesús de Machaca. Por las características formales podemos establecer ciertos patrones constructivos, sin embargo, existen algunas diferencias que podrían responder a ciertas selecciones comunales o de ayllu.

Si bien en ambos casos, cerámica e iglesias, existe una fuerte presencia de los grupos que ejercen el poder, no debemos dejar de lado a los componentes que hacen entrar en acción a los pobladores locales. Es así que la producción, a manera de imitación, de la Mayólica Contisuyo Local fue elaborada posiblemente por los alfareros locales, para cubrir diversas necesidades de grupo o personales. $\mathrm{Y}$ en las iglesias, es claro que la mano de obra eran los comunarios, por lo tanto de alguna forma lograron plasmar ciertos atributos en las iglesias que ellos construían, resaltando esos bloques de cobre, que podría hacer referencia a las minas, lugares de trabajo de muchos machaqueños en la época colonial.

Por último debemos mencionar que los trabajos realizados marcan un inicio en la investigación de sitios arqueológicos de períodos históricos en Jesús de Machaca, esperando ser solamente la apertura para que investigadores noveles puedan incursionar en esta temática. Con los datos presentados notamos la necesidad de continuar con los análisis cerámicos de estos períodos, esto nos podrá establecer una cronología relativa, aspecto muy poco tratado en todo el altiplano boliviano. En cuanto al estudio de iglesias, se debe profundizar en estudios de arqueotectura y generar trabajos multidisciplinarios conjuntamente con fuentes historiográficas. 
Teoría y Práctica de la Arqueología Histórica Latinoamericana | Año VIII. Vol. 8 | 2019

ISSN en línea: 2591-2801 | ISSN versión impresa: 2250-866X

\section{Agradecimientos}

En primera instancia agradecer infinitamente a los pobladores y autoridades del Municipio de Jesús de Machaca por permitirme adentrarme en su territorio para realizar nuestros trabajos. También un agradecimiento al Observatorio del Patrimonio Cultural Arqueológico, a cargo de Jimena Portugal, por proporcionarme los datos geográficos del PCAJM. Una retribución especial a Ariel Morrone y Ricardo Moyano por las directrices brindadas. Por último, agradecer a los evaluadores por sus observaciones y sugerencias.

\section{Notas}

${ }^{1}$ Este proyecto fue llevado a cabo durante las gestiones 2012 - 2015, y tenía como objetivo establecer las relaciones de poder que pudieron existir en el período de transición entre el Período Inka y Colonial Temprano a partir de prospección y excavaciones en el Sitio PATJM 001 en la comunidad de Jesús de Machaca (Arano, 2018).

${ }^{2}$ Los trabajos de registro de sitios arqueológicos en el Municipio de Jesús de Machaca fueron dirigidos por Jimena Portugal durante las gestiones 2016 y 2017, el objetivo fue elaborar un mapa cultural con todos los sitios registrados para los futuros trabajos de gestión patrimonial (Portugal, 2017). El total de sitios registrados que incluyen períodos desde el Formativo Temprano hasta la República fue de 250 (Arano, 2017).

${ }^{3}$ Este tipo cerámico es descrito por Ravines y Villiger (1989) como una expresión de Santiago de Pupuja y Pucará, del departamento de Puno (pp. 175-180). De igual forma Ríos (2010) habla de una cerámica de Puno (pp. 37-44), donde engloba todas estas tradiciones como una escuela que tiene data desde períodos coloniales con el establecimiento de algunos talleres que fabricaban esta cerámica vidriada.

${ }^{4} \mathrm{Si}$ bien el autor no hace referencia a un tipo específico de mayólica, podemos inferir, a partir de las imágenes, que se trataría de mayólica Contisuyo más allá Polícromo (Ulloa, 2010: 249, Foto № 49).

${ }^{5}$ Jamieson (2001: 54-55) comete un error al mencionar que, tanto Rice como Tschopik, infieren que la mayólica Contisuyo tiene a Bolivia como posible fuente de producción, puesto que la comunidad de Pupuja se encuentra en el departamento de Puno, Perú.

${ }^{6}$ El concepto de trucho, en gran parte del altiplano de La Paz hace referencia a aquello que es una copia del original y guarda gran similitud en su presentación formal.

${ }^{7}$ La familia Fernández Guarachi fue un linaje cacical de Jesús de Machaca desde el S. XVI hasta el S. XVIII (Morrone2010a), siendo don Pedro Fernandez Guarachi quien mandó a construir la iglesia en 1679 (Choque, 1994).

${ }^{8}$ Los primero registros de los ayllus de Jesús de Machaca corresponden al Archivo General de la Nación IX, 20-4-4, que logra recuperar Morrone (2010b, p. 449). En el mismo se menciona a los siguientes ayllus: Ylatiti, Sulcatiti, Chama, Guaguatata, Achuma, Cuipa, Parina, Collire, Conco, Challaya, Calla, Ancoaqui, Titicana, Challaya Titicana.

\section{Referencias Bibliográficas}

ALBARRACÍN, J. (1996). Tiwanaku: arqueología regional y dinámica segmentaria. La Paz, Bolivia: Plural Editores.

ALBO, X. (1972). Dinámica de la estructura inter comunitaria de Jesús de Machaca. América Indígena, 
Teoría y Práctica de la Arqueología Histórica Latinoamericana | Año VIII. Vol. 8 | 2019

ISSN en línea: 2591-2801 | ISSN versión impresa: 2250-866X

32(3), 773-816.

ALBO, X. (1996). Iglesia, indios y poder en Jesús de Machaqa, siglos XVII-XX. Anuario de la Academia boliviana de historia eclesiástica, 2, 35-50.

ALBO, X. (2012). Tres municipios andinos camino a la autonomía indígena: Jesús de machaca, Chayanta y Tarabuco. La Paz, Bolivia: Centro de Investigación y Promoción del Campesinado.

ALEJO, M. (2013). Continuidad y cambio cultural entre los periodos inca y colonial (1440 -1534 d.C.) en un contexto urbano del Santuario de Copacabana: Departamento de La Paz - Provincia Manco Cápac (tesis de grado). La Paz, Bolivia: Universidad Mayor de San Andrés. Ms.

ANTEZANA, V. (2016). Patrones de consumo cerámico en la Casa Sarabia durante la Colonia y la República. Textos Antropológicos, 17(1), 69-91.

ARANO, S. (2015a) Propuesta de Afinamiento para la Secuencia Cerámica en Sitios Pacajes. En Museo Nacional de Etnografía y Folklore (Ed.), Anales de la XXVIII Reunión de Anual de Etnología - La Rebelión de los Objetos. Enfoque Cerámico (pp. 113-132). La Paz, Bolivia: Museo Nacional de Etnografía y Folklore.

ARANO, S. (2015b) Relación entre el Poder y los Centros Político - Ideológicos durante el momento de Transición Del Horizonte Tardio a la Colonia (tesis de grado). La Paz, Bolivia: Universidad Mayor de San Andrés.

ARANO, S. (2017). Sitios registrados en el Catastro Arqueológico. En J. Portugal (Ed.), Catastro Arqueológico del Municipio de Jesús de Machaca (pp. 49-154). La Paz, Bolivia: Plural Editores.

ARANO, S. (2018). El tambo de Jesús de Machaca. Investigaciones Arqueológicas y las relaciones de poder. La Paz, Bolivia: Gran Elefante; Gobierno Autónomo de Jesús de Machaca; Instituto de Investigaciones Antropológicas y Arqueológicas.

BARNADAS, J. (1975). Apuntes para una historia aymara. La Paz, Bolivia: Centro de Investigación y Promoción del Campesinado.

BEJARANO, O. (2011). Investigaciones arqueológicas en Tahuapalca - Cebollullo: Un cuartel militar en los inicios de la República (tesis de grado). La Paz, Bolivia: Universidad Mayor de San Andrés.

BENAVENTE, G. (2018). Representaciones de las sirenas en la mentalidad de la población del sur andino: Arequipa (tesis de grado). Arequipa, Perú: Universidad Nacional de San Agustín de Arequipa.

CAYO, L. (2010). Arquitectura religiosa colonial en Santa Cruz la Vieja 1561-1604 (tesis de grado). La Paz, Bolivia: Universidad Mayor de San Andrés.

CHOQUE, R. (1986). La masacre de Jesús de Machaca. La Paz, Bolivia: Ediciones Chitakolla.

CHOQUE, R. (1988). Historia de Machaqa. La Paz, Bolivia: Centro de Investigación y Promoción del Campesinado y SATAWI.

CHOQUE, R. (1990). Una marka aymara: Jesús de Machaqa. Historia, 21, 1103-1117. 
Teoría y Práctica de la Arqueología Histórica Latinoamericana | Año VIII. Vol. 8 | 2019

ISSN en línea: 2591-2801 | ISSN versión impresa: 2250-866X

CHOQUE, R. (1994). Una iglesia de los Guarachi en Jesús de Machaca (Pacajes-La Paz). En G. Ramos (Comp.), La Venida del Reino. Religión, evangelización y cultura en América. Siglos XVI-XX (pp. 135-150). Cuzco, Perú: Centro Bartolomé de Las Casas.

CHOQUE, R. y Ticona, E. (1996). Jesús de Machaqa: La marka rebelde. Sublevación y masacre de 1921. La Paz, Bolivia: Centro de Investigación y Promoción del Campesinado.

CRUZ, P. y TÉREYGEOL, F. (2018). El mineral rebelde. El lado indígena de la producción de plata durante los primeros momentos de la Colonia (Bolivia, Siglos XVI-XVII). Revista de Arqueología Histórica Argentina y Latinoamericana, 12, 37-62.

FOUCAULT, M. (1976). Vigilar y castigar. Buenos Aires, Argentina: Siglo Veintiuno Editores.

GANGUI, A., Gonzáles, C., Perera, A. y Belmonte, J. (2016). La orientación como una seña de identidad cultural: las Iglesias históricas de Lanzarote. Tabona, 20, 105-128.

GANGUI, A., Guillén, A. y Pereira, M. (2016). La orientación de las iglesias andinas de la región de Arica y Parinacota, Chile: Una aproximación arqueoastronómica. Arqueología y Sociedad, 32, 303-322.

GISBERT, T. (2004). Iconografía y mitos indígenas en el arte. La Paz, Bolivia: Gisbert y Cia.

GONZALES-GARCÍA, C. (2015). La orientación de las iglesias Prerrománicas de Galicia: análisis y resultados preliminares. Estudos do Quaternário, 12, 133-142.

GRUPO ALFA. (2014). Proyecto para el desarrollo del turismo comunitario en el municipio de Jesús de Machaca 2007 - 2008. Informe inédito ubicado en los archivos del Gobierno Autónomo Municipal de Jesús de Machaca. La Paz, Bolivia.

INSTITUTO GEOGRÁFICO MILITAR. (2012). Carta Topográfica de Jesús de Machaca. Documento ubicado en el repositorio del Instituto Geográfico Militar de Bolivia con código 5843-IV. La Paz - Bolivia.

JAMIESON, R. (2001). Majolica in the Early Colonial Andes: The Role of Panamanian Wares. Latin American Antiquity, 12(1), 45-58.

JANUSEK, J. (2003). Vessels, Time, and Society: Toward a ceramic chronology in the Tiwanaku heartland. En A. Kolata (Ed.), Tiwanaku and its hinterland 2: Archaeology and paleoecology of an Andean civilization (pp. 30-94). Washington D.C., USA: Smithsonian Institution Press.

JANUSEK, J. (2013). Jesús de Machaca before and after Tiwanaku: A Background of Recent Archaeology at Khonkho Wancane and Pukara de Khonkho. En A. Vranic y A. Levine (Eds.), Advances in Titicaca Basin Archaeology-2. Monographs Book 77 (pp. 7-22). Los Angeles, USA: Cotsen Institute of Archaeology Press.

JORDÁN, W., CASTEDO, L., CHUQUIMIA, C., JIMÉNEZ, S., VEGA, V., MENA, R. y QUENTA, S. (2011). Jesús de Machaca y San Andrés de Machaca. Descripción de la situación social, política, económica y cultural. La Paz, Bolivia: Fundación MachaqaAmawt’a.

KELLOWAY, S., VAN VALKENBURGH, P., IÑANEZ, J., DUSSUBIEUX, L., QUILTER, J, y GLAS- 
Teoría y Práctica de la Arqueología Histórica Latinoamericana | Año VIII. Vol. 8 | 2019

ISSN en línea: 2591-2801 | ISSN versión impresa: 2250-866X

COCK, M. (2018). Identifying New World majolica from 16th-18th Century sites on Peru's north coast. Journal of ArchaeologicalScience: Reports, 17, 311-324.

LEMUZ, C. (2006). Patrones de Asentamiento Arqueológico en el área de influencia del Sitio de Khonkho Wankane. En Janusek, J y Plaza, V. (Eds.), Khonkho Wankane: Segundo informe preliminar del proyecto arqueológico Jach’a Machaca (pp. 5-44). Informe en posesión de la Unidad de Arqueología y Museos. La Paz, Bolivia.

MÉNCIAS, J. (2009). Huacas sagradas y el proceso de extirpación de idolatrías: el caso de la Iglesia de San Sebastián visto desde la cerámica. Khana, Número especial del Bicentenario de la Revolución de 1809, 43-53.

MORRONE, A. (2010a). Legitimidad, genealogía y memoria en los andes meridionales: los Fernández Guarachi de Jesús de Machaca (Pacajes, siglos XVI-XVII). Memoria Americana, 18(2), 211-237.

MORRONE, A. (2010b). Clero rural y liderazgo étnico en el Corregimiento de Pacajes: la antigua Iglesia de Jesús de Machaca (Siglo XVII). Anuario de Estudios Bolivianos, Archivísticos y Bibliográficos, $16,445-475$.

MORRONE, A. (2013). Estrategias estatales y liderazgo étnico en el corregimiento de Pacajes (15381620). En A.M., Presta (Ed.), Aportes multidisciplinarios al estudio de los colectivos étnicos Surandinos. "Qaraqara-Charka Reflexiones a tres años después” (pp. 343-372). La Paz, Bolivia: Plural Editores; Instituto Francés de Estudios Andinos.

PÉREZ, A. (2014). Arqueología en el Río Desaguadero. Excavaciones en Iruhito. La Paz, Bolivia: Producciones Gráficas Junior.

PÉREZ, A. (2017). Guía Cerámica. La cerámica de la cuenca del Río Desaguadero. La Paz, Bolivia: Instituto de Investigaciones Antropológicas y Arqueológicas; SOIPA Ltda.

PORTUGAL, J. (2017). El Catastro Arqueológico como parte de la Cartografía Cultural. En J. Portugal (Ed.). Catastro Arqueológico del Municipio de Jesús de Machaca (pp. 15-26). La Paz, Bolivia: Plural Editores.

RAVINES, R. y VILLIGER, F. (1989). La cerámica tradicional del Perú. Lima, Perú: Los Pinos.

RENDÓN, P., FREDERICKSEN, E., SALVATIERRA, D., MÉNCIAS, J. y TRIGO D. (2007). La Iglesia de San Sebastián. Una mirada desde la Arqueología. En: Museo de Etnografía y Folklore (Ed.), Memorias de la XX Reunión Anual de Etnología: “ItineranciasIdentitarias, permanencias y cambios sociales”, Tomo I (pp. 95-108). La Paz, Bolivia: Museo de Etnografía y Folklore.

RICE, P. (1997). Tin-enameled wares of Moquegua, Peru. En G. Smith y P. Fournier (Eds.), Approaches to the historical archaeology of México, Central and South America (pp. 173-180). Los Angeles, USA: The Institute of Archaeology, University of California.

RICE, P. y NATT, W. (2013). Ceramic spatialization: southern styles. En P. Rice (Ed.), Space-Time Perspectives on Early Colonial Moquegua (pp. 281-308). Boulder, USA: University Press of Colorado. 
RÍOS, S. (2010). La cerámica tradicional peruana. Un acercamiento desde la Historia del Arte. Revista Artesanías de América, 70, 26-51.

RIVERA, S. (1978). El mallku y la sociedad colonial en el siglo XVII: el caso de Jesús de Machaca. Avances, 1, 7-27.

DE LA ROCHA, S. (2013). Arqueología urbana y arquitectura en Tiwanaku: El Hogar Tiwanaku (tesis de grado). La Paz, Bolivia: Universidad Mayor de San Andrés.

SAMANEZ, R. (2011). Las iglesias de Apurímac y Chumbivilcas en el sur peruano: una nueva perspectiva del barroco andino. Memoria del II Encuentro Internacional sobre Barroco. Barroco y fuentes de la diversidad cultural, 23, 183-194.

SCHÁVELZON, D. (2001). Catálogo de Cerámicas Históricas de Buenos Aires (Siglos XVI-XX). Con notas sobre la región del Río de la Plata. Buenos Aires, Argentina: Fundación para la Investigación del Arte Argentina; Telefónica; F.A.D.U.-U.B.A.; C.A.U. Recuperado de http://www.danielschavelzon.com.ar/?p=2442

TICONA, E. (1990). Historia oral de los aymaras de Qhunqhu San Salvador de Jesús de Machaqa. Testimonios aymara/castellano. La Paz, Bolivia: Centro de Investigación y Promoción del Campesinado.

TICONA, E. (1991). JiwasanakanSartawisa, Nuestra historia. Jesús de Machaqa y AyoAyo. La Paz, Bolivia: Centro de Investigación y Promoción del Campesinado.

TICONA, E. (1993). La lucha por el poder comunal: Jesús de Machaca, 1919-1923 y 1971-1992 (tesis de grado). La Paz, Bolivia: Universidad Mayor de San Andrés.

TICONA, E. y ALBO, X. (1997). Jesús de Machaqa: La marka rebelde: 3 La lucha por el poder comunal. La Paz, Bolvia: Centro de Investigación y Promoción del Campesinado; Centro de Documentación e Información.

TORRICO, M. (2013). Ocupación y reocupación de la hacienda de Cusijata Copacabana, Bolivia; de la colonia a la república (tesis de grado). La Paz, Bolivia: Universidad Mayor de San Andrés.

TSCHOPIK, H. (1950). An Andean Ceramic Tradition in Historical Perspective. American Antiquity, 15 (3), 196-218.

ULLOA, D. (2010). La explotación aurífera en el sitio de Maukallajta durante el Período Colonial 1684 - 1781 (tesis de grado). La Paz, Bolivia: Universidad Mayor de San Andrés.

VACA DE CASTRO, C. (1908[1543]). Ordenanza de Tambos. Distancias de unos a otros. Modo de cargar a los indios y obligaciones de las justicias respectivas. Hecho en la ciudad del Cusco el 31 de mayo de 1543. Lima, Perú: Boletín de la Sociedad Geográfica de Lima.

VAN BUREN, M. (1999). Tarapaya: An Elite Spanish Residence near Colonial Potosí in Comparative Perspective. Historical Archaeology, 33(2), 101-115.

VAN BUREN, M. y COHEN, C. (2010). Technological changes in silver production after the spanish conquest in Porco, Bolivia. Boletín del Museo Chileno de Arte Precolombino, 15(2), 29-46. 
VILLANUEVA, J. (2014). Moldeando la vida. La colección de Cerámica del Museo de Etnografía y Folklore, según la cadena de producción. La Paz, Bolivia: Museo Nacional de Etnografía y Folklore.

ZIMBRÓN, R. y MOYANO, R. (2015). La fiesta de la Virgen de Guadalupe asociado a un marcador presolsticial en la parte norte de la cuenca de México. En L.C. Borges (Org.), Diferentes Povos, Diferentes Céus e Saberes Nas Américas: Contribuições da Astronomia Cultural para a História da Ciência (pp. 126-151). Rio de Janeiro, Brasil: Museo de Astronomia e Ciências, Afins - MAST.

Recibido: 12 de marzo de 2019

Aceptado: 15 de mayo de 2019 